\title{
Setorialidade ou intersetorialidade? O caso das políticas públicas de lazer em Brotas, São Paulo
}

\author{
Olívia Cristina Ferreira Ribeiro* \\ Sílvia Cristina Franco Amaral*
}

*Departamento de Educação Física e Humanidades, Faculdade de Educação Física, Universidade Estadual de Campinas, Campinas, SP, Brasil.

\section{Resumo}

0 objetivo desta pesquisa foi analisar as políticas públicas de lazer de Brotas/SP, na gestão municipal de 2009-2012 e se a intersetorialidade estava presente nessa gestão. 0 foco foram as secretarias que mantinham ações sobre o tema (Esportes e Cultura, Turismo, Meio Ambiente, Educação e Ação Social). Analisamos se a setorialidade ou a intersetorialidade estavam mais presentes na gestão de políticas públicas de lazer do município. Como método, usamos a análise documental, observações das reuniões e entrevistas semiestruturadas com gestores e servidores daquelas secretarias. Concluimos que, ao se pensar na efetivação do direito ao lazer, as políticas públicas implementadas em Brotas ainda são muito tímidas. Elemento catalisador, as práticas corporais de lazer na natureza se apresentam muito restritas ao cidadão brotense, tornando-se um privilégio para o turista que pode pagar operadoras que, de certo modo, privatizaram espaços naturais de interesse público. Assim, antes da defesa da intersetorialidade, é fundamental a materialização do lazer como política setorial forte e com gestores e técnicos com competência técnica e política, capazes de defender e fazer valer suas posições no jogo político. Há que se pensar que tal fato também decorre de uma sustentação argumentativa em prol da democratização do lazer.

PalavRAS-Chave: Lazer; Políticas públicas; Gestão setorial; Gestão intersetorial.

\section{Introdução}

O lazer é um direito social, previsto na Constituição Federal de 1988: "[...] o que nos indica que ele foi considerado, no momento de construção de tal Constituição, um bem essencial aos cidadãos e ao seu bem-estar e o acesso a ele foi considerado um fator condicionante da cidadania"(p. 13) ${ }^{1}$.

Um direito social - diferentemente dos direitos civis e políticos - deve ser garantido à população por meio de políticas públicas de Estado e de governo. As políticas públicas são consequência da atividade política, por serem escolhas entre um quadro de conflitos de preferências quanto às concepçôes sobre a ação do Estado, à alocação de recursos etc., de acordo com MenicuCCI ${ }^{2}$. As políticas públicas são formuladas e implementadas para os diversos setores que compóe o setor público (saúde, educação, cultura, esporte etc). À essa divisão denominamos setorialidade, que está segmentada em departamentos, diretorias ou, ainda, em secretarias.

Menicucci $^{2}$, Costa 3 , Bonalume ${ }^{4}$ e Amaral e $\operatorname{Costa~}^{5}$ acreditam que o lazer, como conteúdo de uma política pública, devido às suas características interdisciplinares, deve ser formulado e executado por diversas secretarias. Ainda defendem que uma das formas de se preencher essa lacuna é por meio da implantação da intersetorialidade. Para MenicuCCI ${ }^{6}$, "[...] a intersetorialidade é uma nova forma de abordar os problemas sociais, enxergando o cidadão em sua totalidade e estabelecendo uma nova lógica para a gestão da cidade" (p. 11).

Isso significa integrar programas e ações públicas das diversas secretarias municipais, tanto na 
formulação quanto na implementação e na avaliação delas. AвREU ${ }^{7}$ conceitua a intersetorialidade como uma "ação política e técnica de articulação entre setores visando à construção, reafirmação ou oposiçâo a projetos coletivos que potencializam ou obstaculizam interesses coletivos" (p. 111). A intersetorialidade pretende superar a forma segmentada e desarticulada como, normalmente, acontecem as açôes públicas, "encapsuladas nos vários nichos setoriais ou disciplinares" (p. 11) ${ }^{6}$. A partir da sua adoção, há um esforço de síntese de conhecimentos, de articular práticas para unificar o modo de produção de conhecimento e as estratégias de ação.

BonAlume ${ }^{8}$ acrescenta que " $[. .$.$] a$ intersetorialidade nas políticas sociais é tema de estudos significativos no país, porém as de lazer e esporte ainda enfrentam limitações e indicam pouca densidade de informaçóes sobre o tema” (p. 14).

Contudo, recentes pesquisas sobre a intersetorialidade no lazer e seus resultados na gestão pública, como as de $\operatorname{Costa}^{3}$, Bonalume $^{8}$ e Silva ${ }^{9}$, nos alertam para um quadro preocupante em relação a tais políticas, já que as análises demonstram que, muitas vezes, nem setorialmente estas têm merecido valor e atenção, igual ou próximo, ao dirigido a outros direitos sociais. Isso certamente se deve, em parte, à cultura política, já que, mesmo que a Constituição tenha garantido ao lazer status de direito social, fato considerado como uma relevante inovação e que proporcionou a formulaçáo de programas em diferentes esferas federativas, há muito a ser feito para garantir a sua efetivação para a maioria dos brasileiros. Historicamente, as políticas públicas de lazer no país se apresentaram, em sua maioria, com caráter excludente, fragmentadas e, ainda, funcionalistas, conforme denuncia AMARAL ${ }^{10}$.

É possível implementar açôes intersetoriais ou conjuntas sem uma setorialidade edificada?

Após estes apontamentos iniciais e o contato com a cidade de Brotas, que se intitula a capital brasileira do turismo de aventura, pensamos que as políticas públicas daquele município poderiam ser elaboradas e implementadas por meio de açóes intersetoriais, associando esforços de diferentes secretarias e/ou departamentos, especialmente em torno do tema do lazer na natureza. Por esta razão, resolvemos pesquisar as políticas de lazer daquela cidade. O debate teórico sobre intersetorialidade balizou nossas análises e investigamos três importantes dimensões apontadas pela literatura como fundamentais na sua consecução: a cultura política, as estruturas organizacionais e as açóes em si, enfocando o seu modo de gestão.

A cultura política pode ser definida, segundo Martins ${ }^{11}$, "[...] como o sistema de crenças, condutas e orientaçôes avaliativas com respeito ao governo e à política que molda o comportamento político individual ou coletivo.” (p. 49). Diz respeito aos padrôes de comportamento e às atitudes dos diversos atores políticos na gestão pública. É historicamente construída. De acordo com Martins ${ }^{11}$.

[...] a cultura política do Brasil é profundamente enraizada em uma herança colonial patrimonialista. Apesar das enormes mudanças econômicas e sociais que o país sofreu, o nepotismo, o favoritismo e o clientelismo, sob diferentes formas, tornaram-se características culturais persistentes [...]. Isso moldou tanto a percepçáo da sociedade com respeito ao Estado como a organização da administração pública (p. 9).

Quanto ao patrimonialismo, no Brasil, é possível caracterizar, segundo Paula ${ }^{12}$, três tipos: o tradicional, o burocrático e o político. O patrimonialismo está diretamente imbricado com o nepotismo, uma vez que, quando presentes na administração pública, os indivíduos que exercem cargos e funçóes públicas são escolhidos de acordo com questóes pessoais, e essas escolhas não são baseadas na meritocracia. No nepotismo, parentes e amigos são favorecidos e contratados para a ocupação de cargos públicos. Embora existam leis que proíbam essa prática, ambos, o patrimonialismo e o nepotismo, estão presentes no cenário político brasileiro nas três esferas (federal, estadual e municipal). O corporativismo e o clientelismo se caracterizam quando administradores públicos favorecem amigos ou há trocas de favores e/ou vantagens durante sua gestão. Martins ${ }^{11}$ ao fazer uma revisão sobre a administração pública e apresentar a construção do aparelho do Estado no Brasil enfatiza que o clientelismo está tão arraigado em nossa cultura política que há uma predisposição da sociedade em aceitá-lo como uma prática 'normal'. Afirma, ainda, que sua persistência como padrão político, muitas vezes, se transformou, em nosso país, em práticas corruptas.

As estruturas organizacionais dizem respeito ao como estão distribuídas as áreas no setor público (saúde, educação, esporte, cultura, obras, 
e assim por diante), normalmente divididas por setores, departamentalizadas, com vários escalóes hierárquicos. Inojosa ${ }^{13}$ afirma que tais características se juntam a um número de práticas na organização do trabalho, por exemplo: "[...] centralização decisória, dicotomia entre planejamento e execução, sigilo, ocultação de informações, formalização excessiva e distanciamento do cidadão e do usuário" (p. 38).

A descentralização política e administrativa foi prevista na Constituição de 1988 , por meio da transferência de recursos e de atribuiçóes para os estados e municípios, e foi delegada autoridade aos administradores públicos. Permitiu-se, assim, aos municípios, autonomia para administrar e aplicar os seus recursos com vistas à qualidade de vida dos cidadãos. Mas a descentralização, que é importante para a intersetorialidade, é aquela que ocorre no próprio município, por meio de reformas administrativas, e se articula com outra categoria, a de território. De acordo com Menicucci ${ }^{2}$, "[...] a descentralização intramunicipal fortalece a autonomia de administraçóes regionais, deslocando a gestão e a execução das açôes do centro para a periferia com a incorporação da lógica da territorialidade" (p. 150). Essa mudança auxilia na integração das açóes por meio da redefinição das funçóes e da forma de articular as unidades organizacionais da Prefeitura.

Outro aspecto fundamental da gestáo é o compartilhamento de açóes entre diferentes setores, não só no intuito de enxugamento financeiro, mas fundamentalmente em prol da melhoria das políticas e do alcance destas pela população. A gestão compartilhada considera novos arranjos institucionais nas políticas públicas e prevê o estabelecimento de formas inovadoras de articulação entre Estado, sociedade civil e mercado. Há uma tendência à inclusão de novos atores na formulação e na implementação das políticas públicas, principalmente as municipais ${ }^{14}$. Dessa forma, projetos e programas são articulados em rede em diversas organizaçôes e entidades em torno de um problema de interesse público. De acordo com Pinto ${ }^{15}$, essas redes são constituídas de "[...] atores que vão desde comunidades de especialistas até movimentos sociais, redes societárias temáticas, atores governamentais, dentre outros que por meio da cooperação buscam atingir objetivos comuns" (p. 64). São atores, técnicos ou profissionais que compartilham valores e buscam influenciar a implementação de uma política pública, esclarece a autora. MenicucCi ${ }^{6}$ acrescenta que a metáfora de uma rede como um conjunto de nós sem centro é conhecida nas políticas sociais, mas ganha ênfase na perspectiva da intersetorialidade.

Postos esses conceitos com os quais operaremos, é preciso situar nosso locus. Brotas é um pequeno município do interior paulista, cidade famosa nacionalmente por suas belezas naturais e pelo lazer na natureza. O desenvolvimento turístico ampliou a oferta de lazer para os moradores e turistas pelo setor privado e, ao mesmo tempo, modificou a estrutura administrativa da Prefeitura Municipal. Secretarias foram desmembradas, outras criadas, bem como surgiram também os Conselhos Municipais de alguns dos direitos sociais, estruturas essas que, em tese, devem garantir a participação da sociedade civil. Houve, ainda, mudanças no calendário de eventos de lazer da cidade e um incremento neles, bem como uma maior participaçáo do Poder Público na sua promoção e apoio. É possível observar que as políticas de lazer estão valorizadas por açóes em contato com a natureza e pela relaçáo do corpo nesse espaço. Supusemos que elementos como natureza, aventura, lazer e turismo pudessem ser catalisadores das políticas públicas da cidade e poderiam motivar uma gestáo intersetorial do lazer.

Dessa forma, os objetivos do estudo foram verificar como se caracterizavam as políticas públicas de lazer em Brotas na gestão 2009/2012 no que se refere à presença da intersetorialidade e diagnosticar qual a relação mantida entre as diversas secretarias ligadas ao lazer, como as de Turismo, Esportes e Cultura, Meio Ambiente, Educação, Saúde e Ação Social.

\section{Método}

Utilizamos a pesquisa documental para analisar as legislaçóes pertinentes ao lazer de Brotas (Lei Orgânica, Plano Diretor, leis específicas do Turismo, do Esporte e da Cultura). A observação participante complementou a análise documental ${ }^{16}$ nas 10 reuniôes das Secretarias Municipais de Turismo, 
Diretorias de Esporte e Cultura pertencentes à Secretaria de Esportes e Cultura, as nove do Conselho Municipal de Turismo (Comtur) e as três do Conselho Municipal de Defesa do Meio Ambiente (Comdema). Foram realizadas 17 entrevistas semiestruturadas com os gestores e com servidores das seguintes Secretarias: Esportes e Cultura, Turismo, Meio Ambiente, Educação e Ação Social. Todas as entrevistas foram gravadas, transcritas, enviadas aos participantes por e-mail para aprovação e retornadas. Um termo de consentimento livre e esclarecido foi assinado pelos entrevistados, como previsto no projeto submetido ao Comitê de Ética da Unicamp, cujo parecer é o de número 078698 12.5.0000.5404. Realizamos a análise temática e os temas analisados foram intersetorialidade, integração e cooperação ${ }^{15}$.

QUADRO1- Caracterização dos entrevistados.

\begin{tabular}{|ll|}
\hline Entrevistados & Perfil \\
\hline N. 1 & Arquiteto e urbanista. Servidor desde 2001. \\
N. 2 & Bacharel em Turismo. Gestora desde 2012. \\
N. 3 & Professor de Educação Física. Técnico em Saneamento Ambiental. Graduando em Gestão \\
N. 4 & Ambiental. Servidor desde 1993, Gestor desde 2002. \\
N. 5 & Bacharel em Direito. Ex-gestor (1992-1996; 2004-2008). \\
N. 6 & Engenheira agrônoma. Mestre em Geociências. Servidora desde 2008. \\
N. 7 & Bacharel em Turismo. Pós-graduada em Administração Hoteleira. Ex-gestora. \\
N. 8 & Técnica em Turismo. Servidora desde 2010. \\
N. 9 & Bacharel em Administração de Empresas. Pós-graduada em Marketing. Ex-gestora. \\
N. 10 & Ensino Médio. Servidora desde 1992. \\
N. 11 & Engenharia civil. Ex-gestor (2005-2007) e atual gestor 2012. \\
N. 12 & Professor de Educação Física. Servidor desde 2005. Gestor desde 2009. \\
N. 13 & Bacharel em Educação Física. Servidor desde 2009. \\
N. 14 & Ensino Médio. Escriturária de uma das associaçóes subsidiadas pela Prefeitura Municipal. \\
N. 15 & Pedagoga. Pós-graduada em Direito Educacional. Servidora desde 1992. \\
N. 16 & Pedagoga. Pós-graduada em Língua Portuguesa, Educaçáo Inclusiva e Psicopedagogia. \\
N. 17 & Filósofo e teólogo. Gestor desde 2012. \\
& Assistente Social. Servidora desde 2003. \\
\end{tabular}

\section{Resultados e Discussão}

\section{A cultura política}

Nossa análise das políticas públicas de lazer em Brotas se deteve em algumas categorias que são caras à intersetorialidade, como já comentado anteriormente. No caso do lazer, há uma cultura política que interfere de forma negativa na concepção das mesmas, pois este direito é encarado como necessidade de segunda ordem no município, como mostraremos mais adiante. Em Brotas, a legislação nominalmente valoriza o lazer. $\mathrm{O}$ Plano Diretor da cidade apresenta o lazer e a qualidade de vida dos cidadãos como um de seus princípios, como segue:

\footnotetext{
Organizar a expansão dos núcleos urbanos do município - a cidade, o Distrito de São Sebastião da Serra e o Bairro do Broa - de modo a garantir o acesso de todos os cidadáos ao desfrute do espaço urbano, entendido como direito à moradia, circulação, lazer, infra-estrutura básica, equipamentos e serviços públicos ${ }^{17}$.
}

Outro aspecto, presente na cultura política brasileira, 
é a delegação de secretarias de menor valor a aliados políticos partidários, que estiveram presentes na coligação e ajudaram na eleição do prefeito, governador ou presidente. Muitas vezes, assumem a pasta do lazer dirigentes que não têm formação adequada e nem se preocupam em compor quadro técnico com capacidade de elaborar, coordenar e executar açóes que, minimamente, tangenciem uma teoria e uma linha conceitual sobre o tema. Por exemplo, na cidade de Campinas, durante várias gestóes assumiu um médico como secretário de esporte. No caso de Brotas, o secretário, a época da análise era o filho do prefeito. Contudo, há experiências brasileiras que têm sido exitosas no sentido de modificar essa realidade.

Em relaçáo aos dados da gestáo pública de Brotas aqui estudada, pode-se afirmar que a cultura política se apresenta com padróes muito semelhantes ao exposto pelos autores acima citados. Nas secretarias, que têm açóes de lazer, há técnicos cuja formação poderia nos levar a pensar que alguma mudança no tema lazer poderia acontecer. É possível perceber a formação dos gestores de algumas secretarias, como já citada no quadro um. Porém, o que observamos, durante o período pesquisado, foram velhas práticas. O Secretário de Esportes, Recreação e Cultura era o filho do prefeito, que delegava as açóes aos Diretores de Esporte e Cultura. Iniciou sua gestão em 2009, quando ainda tinha 24 anos. Tinha uma influência direta na gestáo a ponto de ouvirmos de muitos servidores, diversas vezes, que "quem manda na cidade é o filho do prefeito", confirmado posteriormente nos depoimentos da Comissão Parlamentar de Inquérito (CPI). Desse fato, podemos concluir que em Brotas, antes mesmo de uma intersetorialidade, há que se ter uma setorialidade fortalecida e com autonomia. Pois outra característica importante para a intersetorialidade é que haja lideranças técnicas capazes de convencer por argumento, não pela força do cargo que ocupam ou de seus padróes de relacionamento pessoal.

Também a centralização das decisões é descrita pelos autores, Amaral e Costa ${ }^{5}$, como problema na gestáo pública brasileira, compondo a nossa cultura política. Isso pode ser notado nas açóes centralizadoras tomadas pelo prefeito e que afetaram a gestáo do lazer na cidade. Houve, a partir de decisão centrada no prefeito, a diminuição do número de componentes da guarda municipal ambiental que fiscalizava as áreas de proteçáo das nascentes e a prática de turismo de aventura. Não houve fiscalização do número máximo de turistas permitido por lei nos atrativos naturais da cidade. Por isso, os impactos ambientais causados pelo turismo foram observados. Essas não-açóes privilegiam os empresários das agências de turismo do município e trouxeram consequências ambientais graves a todos os munícipes. Esse fato pode ser notado num trecho do diário de campo:

\begin{abstract}
Pela primeira vez nesses seis meses em que venho participando das reunióes do Comtur, observo a discussão sobre a preservação ambiental. Um dos condutores denunciou que o rio Jacaré-Pepira está sendo assoreado e que açôes do Poder Público não foram suficientes para respeitar o meio ambiente. Propôs a reativação da guarda ambiental, que foi diminuída e que náo tem dado conta de fiscalizar as empresas. Perguntei em voz baixa a uma pessoa ao meu lado por qual motivo o voucher não era utilizado. Esta pessoa levantou a questão para todos os presentes. A Secretária de Turismo e a servidora da Sectur presente afirmaram que a Secretaria era totalmente a favor do voucher. Houve uma discussão acalorada sobre a questão, inclusive com os empresários que têm a LITA, pois a exigência desta para todos os empreendimentos do município seria, pelo menos, uma forma de amenizar o problema da não aplicação da lei do voucher (DIÁRIO DE CAMPO, 12/04/2012).
\end{abstract}

No turismo, voucher corresponde a um "documento emitido por uma agência de turismo que comprova junto ao prestador de serviço determinada reserva e o seu pagamento" (p. 149) ${ }^{17}$. Deve conter todas as informaçôes relativas à compra, como nome do passageiro, nome do hotel contratado, período da reserva, entre outras ${ }^{18}$. Por meio de sua emissão, é possível controlar o fluxo de turistas, diária, mensal ou anualmente, em um determinado atrativo turístico natural (elemento da natureza capaz de provocar o deslocamento das pessoas).

Um entrevistado faz consideraçóes no que se refere à falta de cuidado na questão ambiental na gestão:

\footnotetext{
Nessa administração [2009-2012] eu senti que ele não estava tâo empenhado na questão ambiental. A guarda ambiental, ele acabou diminuindo, de quatro guardas, ficaram somente dois e depois ficou um só, ele estava mais preocupado com outras questôes administrativas. Mas ele não teve empenho nas questôes ambientais, pois o meio ambiente já tem um nome, tem uma história e na questão do Município Verde e Azul, ele não empenhou tanto (ENTREVISTADO TRÊS).
}

Em abril de 2012, o prefeito, que governava por meio de uma liminar, foi cassado definitivamente. Ele foi denunciado e acusado de gastos irregulares, desvio de finalidade na utilização dos recursos públicos, ligação elétrica irregular de prédio público e ingerência de seu filho, Secretário de Esportes, Recreação e Cultura. O 
relatório da CPI concluiu pela existência de desvio de finalidade, descumprimento da lei, negligência na administração dos bens do Município, falta de decoro no exercício do cargo de Prefeito Municipal. O prefeito foi cassado no ano de 2010, mas continuou no governo, por meio de uma liminar, até abril de 2012. No entanto, a denúncia foi enviada a outras instâncias superiores, quando, então, o prefeito foi cassado de fato e, no mês seguinte, seu vice assumiu o cargo e ficou até o final da gestão.

A nova gestão foi elogiada pelos servidores e gestores entrevistados, pela transparência e pelo estilo de governar, na visão deles, mais democrática que a administração anterior. Também foi citada uma maior integração entre as diversas áreas.

As negociaçōes entre as secretarias ficam pra conversar depois, mas grosso modo as questôes são compartilhadas, então a gente se encontra e conversa. E eu acho que isso era muito difícil de acontecer no passado, porque ele deixa muito aberto as decisões das coisas, não fica querendo saber os mínimos detalhes. Ele é muito tranquilo, nesse ponto ele deixa a gente muito à vontade para fazer o trabalho, dá carta branca e ele reforça isso dizendo que acredita no nosso trabalho, no nosso profissionalismo, diz que somos todos muito técnicos (ENTREVISTADA DOIS).

A gestão 2012-2012 melhorou.

Nesse ponto, ele tem uma visão mais ampla e isto é importante. Eu acho que ele trabalhou pra isso, a equipe de agora está trabalhando para isto, ficou legal. (ENTREVISTADO TRÊS).

Já a relação entre as secretarias, hoje, tem sido muito boa, temos feito reuniôes junto com o prefeito, o que eu acho muito importante. Como ele tem sido mais aberto, é mais fácil do que com os prefeitos anteriores. Ele quer que haja uma comunicaçáo entre os secretários, que os secretários se comuniquem. Eram situaçóes diferentes, visóes diferentes nos dois governos (ENTREVISTADO DEZ).

Esta gestão, no pouco tempo que lhe restava, buscou o fortalecimento das estruturas administrativas, mas não é possível afirmarmos que houve uma mudança substancial na cultura política a ponto de impactar nas açóes de lazer.

\section{Estrutura organizacional, ações e o dilema entre setorialidade ou intersetorialidade}

A Prefeitura Municipal de Brotas tem como estrutura organizacional as seguintes Secretarias: Planejamento,
Administração e Finanças, Obras e Serviços, Educação, Ação Social, Esportes e Cultura, Saúde, Agricultura, Turismo e Meio Ambiente.

Ao olhar para essa estrutura, em um primeiro momento, parece não haver possibilidade de integração das áreas, como discutem vários autores, como Menicucci ${ }^{2,6}$, Luna $^{19}$, Bonalume ${ }^{4}$ e Pinto ${ }^{20}$. Essa forma de apresentação tradicional, verticalizada e dividida por áreas de especialização é criticada pelos autores, pois fazem com que os servidores fiquem enclausurados em seus setores e deixem de pensar no cidadão como um todo. Os autores afirmam que as políticas públicas podem se resumir a decisóes segmentadas, o que aumenta a fragmentação das políticas. Para se atuar intersetorialmente, de acordo com Amaral e Costa ${ }^{5}$, é necessário haver mudanças nas instituiçóes sociais e em suas práticas. Se não houver órgãos intersetoriais, é indispensável, então, "alterar a forma de articulação dos diversos segmentos da organizaçáo governamental e de seus interesses, privilegiando a integração em prejuízo da setorialização e da autonomização nos processos de trabalho" (p. 12) .

Entretanto, mesmo em uma estrutura setorializada, como a de Brotas, é possível propor e implementar programas, açóes e eventos integrados. Mas acreditamos que isso só ocorre quando setorialmente há lideranças e competência técnica que produzem um consenso suficientemente forte em torno do tema lazer, facilitando o convencimento e a integração com outras áreas.

No caso de Brotas, não há órgãos descentralizados, mas o Plano Diretor previu a descentralização das decisóes com vistas a ampliar a autonomia das Secretarias. No Plano Diretor, no Título II, Capítulo I, Art. 4, apresenta tal questão em uma de suas diretrizes:

[...] promover a descentralização das decisões do Governo Municipal, ampliando gradativamente condiçôes de autonomia para as Secretarias e Autarquias que compóem a Administração Pública, articulando as açóes das mesmas através de Plano de Governo expresso pelo Prefeito Municipal através da Secretaria de Planejamento(p. 4$)^{17}$.

Apesar disso, a criação de órgãos descentralizados, na referida gestão, não foi cumprida. Como comentado anteriormente, é possível açôes integradas mesmo em estruturas organizacionais piramidais. Para analisarmos se houve gestão compartilhada efetivamente ou se setorialmente, o lazer tinha espaço de relevância, estudamos cada uma das secretarias que tinha ação deste tema. Quais açóes de lazer eram feitas? Havia ações compartilhadas? Ou açóes sobrepostas sem 
diálogo? Qual conceito de lazer orientava tais açóes? Foram alguns dos questionamentos que nos guiaram durante o estudo.

Havia açóes de lazer em várias secretarias. A Secretaria de Esportes e Cultura já estava prevista em lei e foi implementada na gestão 2009-2012. Ela se subdividia em dois Departamentos: o de Esportes e Recreação e o outro, o de Cultura. Essa Secretaria oferecia diversos programas, projetos, açóes e eventos nos espaços públicos de lazer na cidade, voltadas aos munícipes, e outros, aos turistas. A Secretaria de Esportes abrangia também a Diretoria de Cultura. Para realizar as atividades, mantinha o Centro Cultural, aberto à população durante a semana. Nesse local, havia a Biblioteca Municipal, com arquivo de livros, assinaturas de revistas e jornais e computadores para uso do público, além de abrigar o Museu do Cotidiano de Brotas. O Centro Cultural ainda abrigava uma sala, com um pequeno palco, em que eram oferecidos à populaçáo eventos artísticos diversos: peças teatrais, shows de música, exposições etc. A Diretoria de Cultura oferecia aulas de música em diversos instrumentos e também canto coral. Era responsabilidade dessa Diretoria a organização da Feira de Artesanato e o desenvolvimento de alguns eventos.

Essa Diretoria ainda organizava os "shows da praça”, em que cantores e músicos de Brotas e outros da região se apresentavam na praça principal, reformada para esta finalidade, mas sem um calendário fixo. Na gestão 2009-2012, esses shows não aconteceram com periodicidade, mas o novo Diretor de Cultura recuperou essa programação, que sempre fez parte da cultura brotense, e promoveu o acesso a mais uma prática de lazer. A Diretoria de Cultura tinha um diálogo próximo com a Secretaria de Turismo e a Associação dos Artistas de Brotas, mas somente em eventos.

Outra Secretaria, a de Ação Social, também oferecia programas de lazer para os brotenses. Esta Secretaria mantinha um local específico para atender os idosos. De acordo com levantamentos realizados nessa Secretaria, esse espaço oferecia ginástica, dança, ioga, hidroginástica, jogos de bingo, palestras e viagens mensais.
A Secretaria de Educação era uma das maiores da Prefeitura Municipal de Brotas. Ela desenvolvia passeios com os alunos das escolas municipais, mas o que nos chamou a atenção foi o fato de a maior parte ser realizada fora de Brotas. Ao questionarmos sobre isto, relataram-nos que a escolha dos roteiros tem relação com os conteúdos curriculares. Em relação a açóes, programas e eventos conjuntos com outras secretarias nas escolas municipais puderam ser destacados: Dia do Ecoturismo, Dia do Turismo, Semana do Meio Ambiente e Oficina de Educação Ambiental.

A Secretaria do Meio Ambiente de Brotas também foi incluída neste estudo, por abarcar açóes, eventos e programas integrados às outras áreas da municipalidade. Tinha como função desenvolver a política relativa à proteção ambiental no município. Aárea ambiental de Brotas era e tem sido referência para outros municípios e de interesse para pesquisadores de diversas áreas e universidades.

A Secretaria de Turismo de Brotas tinha como principal papel manter a atratividade de Brotas e atender os turistas. Para isso, a Secretaria participava de várias feiras e eventos estaduais e nacionais para divulgar a cidade. Também era responsável pela organização e pela execução de vários eventos turísticos e esportivos. Alguns, organizados pelo Poder Público; outros, pela iniciativa privada ou pelo terceiro setor. Nesses dois casos, a Prefeitura Municipal sempre apoiava os eventos de diversas formas: por meio de auxílio financeiro, no fornecimento de mão de obra ou de recursos materiais.

É possível afirmar que as Secretarias aqui estudadas mantinham um diálogo, ainda que os planejamentos fossem tímidos. Os conselhos estudados, Comtur e Condema, eram deliberativos, porém não havia dados suficientes oriundos das observaçóes que nos permitiam afirmar que a participação cidadã ocorria de forma efetiva e que haveria uma descentralização de poder real em Brotas em curto espaço de tempo.

$\mathrm{O}$ quadro a seguir oferece uma visão das açóes de lazer mantidas pelas secretarias estudadas. Nele, procuramos analisar que açóes eram realizadas em conjunto, quais se sobrepunham e quais poderiam compor uma política intersetorial. 
QUADRO 2 - Ações por secretarias e suas interlocuções.

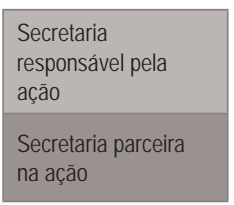

\#\#\#\# - Sobreposição de ações.

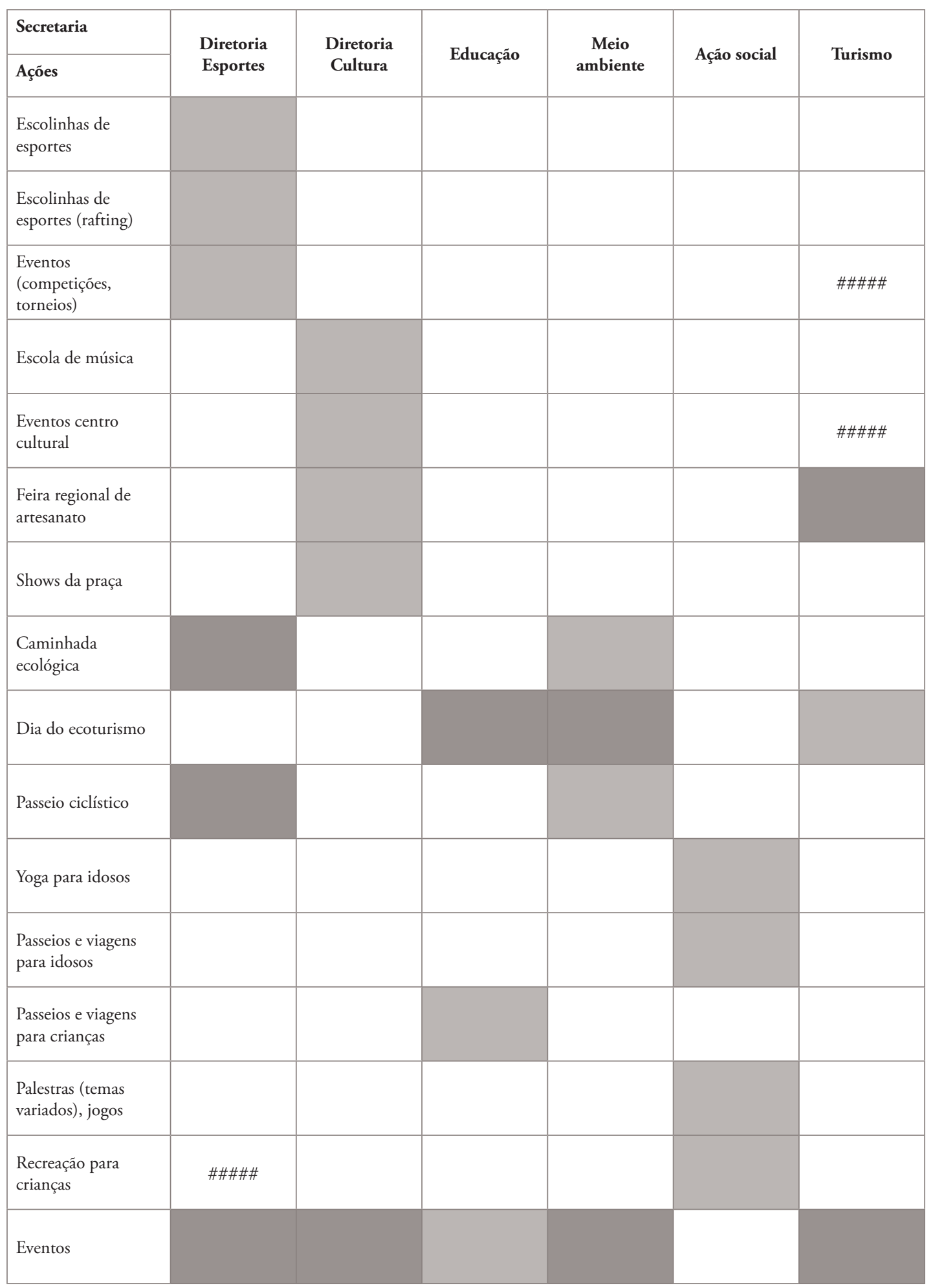


Vemos queo repertório de açóes de Brotas apresentava um lugar em que a secretaria que é responsável pelo lazer é a aquela que oferece os esportes tradicionais. Chamava a atenção o pouco aproveitamento do potencial natural da cidade em prol do cidadáo. Havia em Brotas possibilidades de caminhada e corrida de orientação, cannoing, rafting, boiacross, rapel etc., contudo tais atividades não compunham ações de políticas públicas de lazer, sendo a exceçáo a escolinha de rafting (que, pelas observaçôes, era oferecido numa lagoa poluída, não no rio Jacaré-Pepira). Além disso, notamos em quase todas as açóes apresentadas em Brotas potencial de políticas intersetoriais, contudo, quando estas aconteciam em conjunto, eram feitas em parcerias "frouxas", em que havia colaboração, não havia compartilhamento do planejamento, ação e avaliação. Pressupomos que muito disto se devia ao fato de o lazer ser um tema, uma área que não conseguiu status de importância entre os direitos sociais, o que fazia com que setorialmente profissionais que atuavam nesta área não tivessem força política e muitas vezes nem competência técnica para lidar com demandas e oportunidades.

Outro dado preocupante era que, na gestão 20092012, indícios de intersetorialidade apareceram com mais frequência nos eventos, como citou alguns dos entrevistados, e partiu dos gestores e servidores, sem estímulo do prefeito.

O Esporte nos ajuda, pois realizamos alguns eventos e eles nos auxiliaram. Fizemos um passeio ciclístico, fizemos uma caminhada ecológica, e eles sempre ajudam na organização, houve atividades também no 'Brotão' (ENTREVISTADO TRÊS).

Açôes, eventos e programas em conjunto? Limpeza dos Corredores Turísticos, Seminário Técnico de Condutores de Turismo de Aventura com as Secretarias de Meio Ambiente, Saúde, Vigilância Sanitária, Dia do Turismo, com a Secretaria de Educação (ENTREVISTADA SETE).

Em relação ao lazer, em dois eventos que acompanhamos, pudemos acompanhar o planejamento, a execução e a ocorrência de intersetorialidade. $\mathrm{O}$ primeiro aconteceu pela primeira vez em 2012, o 'Brotas Gourmet'. Teve o objetivo de divulgar para a populaçẫo brotense todos os restaurantes da cidade, por meio de pratos a preços baixos bem como oferecer uma opção de lazer aos munícipes e, ainda, atrair turistas em um mês que costuma ser de pior movimento para o trade , de acordo com dados da Secretaria de Turismo. Aconteceu no Centro Comunitário, houve apresentação da orquestra de viola e de um artesão que confecciona violas. Este apresentou o processo de fabricaçáo deste instrumento. $\mathrm{O}$ evento ocorreu em duas noites.

O 'Dia do Turismo' envolve a organização pelo Turismo, o Esporte, que empresta o transporte, a Educação, que permite que a gente visite as escolas para realizar o sorteio, a Secretaria de Transportes, a Vigilância Sanitária, que emite uma licença para o café da manhâ, e o trade, que fornece as vagas (ENTREVISTADA SETE).

Embora esses dois eventos tenham podido comprovar que o planejamento em conjunto e a cooperação dos organizadores do setor privado e público dão resultados positivos, alguns questionamentos se fazem necessários. O 'Dia do Turismo' acontece uma vez por ano e somente num período do dia. Por que não poderia ocorrer durante um dia inteiro? Por que não se oferece outras vezes no ano? Por que não há programas com essas práticas de lazer na natureza que as Secretarias de Esporte, Turismo, Educação e Meio Ambiente podem planejar e executar em conjunto?

Em relação aos recursos humanos com competência técnica setorial sobre lazer em Brotas, é possível afirmar que não há equipes intersetoriais específicas para açôes e eventos integrados. Mas o fato de algumas secretarias terem um pequeno número de servidores (por exemplo, três servidores na Secretaria de Turismo e um na Secretaria de Esportes e Cultura) fazia com que eles se dividissem na organização das tarefas, açôes e eventos.

Por fim, afirmar o lazer oferecido por meio de eventos pontuais certamente enfraquece tal política, que, prevista pela constituição de 1988 como direito social, reverbera em leis estaduais e municipais sem, no entanto, compor mudanças reais.

O fortalecimento de uma área depende também do entendimento conceitual. Das entrevistas por nós realizadas, notamos, em poucas delas, algo próximo a uma conceituação sobre o tema. Abaixo, alguns trechos em que podemos notar o conceito de lazer que permeia a atuação neste setor.

\footnotetext{
O impacto positivo é a constituição desses lugares prazerosos, perto do rio, o contato com a natureza. Nós temos aqui parques, cachoeiras. Hoje, a gente consegue ver famílias sentar e conversar, não tinha, chegava domingo e era shopping em São Carlos. Hoje, nós temos lugar aqui pra almoçar que não deixam a desejar para ninguém, acho que esse ponto é o principal. Além de o turismo ter trazido esse bem viver e, assim, a segurança para essas pessoas - porque, por ser turística, a administração tem que voltar ainda mais
} 
os olhares para a segurança - e tudo que envolva o bem viver das pessoas, porque, se a cidade não for boa para quem mora, náo vai ser boa para quem vem visitar. Eu acho que o turismo deu isso para as pessoas, [...] Entáo, o turismo faz com que o governo olhe mais por isso, esse é o ponto positivo. Além do efeito multiplicador, que é o ciclo: quando você vê um restaurante funcionando, você não sabe que ali é um senhor quem cuida da horta municipal, que cuida da verdura, do leite, pessoas daqui, são os artesãos da cidade. Então, se tem certa valorização em toda a cadeia. Então, eu não consigo ver efeito negativo, só positivo (ENTREVISTADA SEIS).

A principal mudança foi a infraestrutura, até o calçadão da marginal foi com verba do turismo, mas não é lazer diretamente, mas é um espaço que te convida a caminhar, talvez o mais harmonioso de Brotas. Temos que falar mais isto, acho que o trabalho do bom prefeito é mostrar o quanto Brotas recebe de verba do Ministério do Turismo. Outra coisa que eu poderia citar, foi no tempo da secretária [...], quando ela trouxe eventos. Sempre pedia uma contrapartida social e isso se revertia, muitas vezes, em lazer gratuito para a comunidade, como exemplo o FATU [Festival de Filmes de Turismo de Aventura]. Os brotenses puderam participar de graça, tanto como atletas como iniciantes, abriu-se uma categoria para estas pessoas, para que os integrasse à comunidade, os moradores ao evento. Nesse caso, mais pontual, vai muito do secretário ter uma visáo de integrar o lazer, trazer, para quem mora aqui, os benefícios do turismo (ENTREVISTADA OITO).

O que eu sinto é que os próprios moradores conhecem pouco os atrativos, os pontos turísticos, porque, antigamente, os moradores usufruíam mais, as cachoeiras eram abertas. A partir do momento em que começou esse movimento do turismo, tudo é pago, então os moradores aproveitam pouco. Foi positivo para a cidade, em termos de comércio, mas para os moradores, de certa forma, privou do lazer, deveria haver mais incentivo, fazer mais barato para a população, porque é importante, de repente o turista pergunta uma informação para algum brotense e ele não sabe, não conhece. Infelizmente, para o morador, é difícil o acesso ao lazer (ENTREVISTADA CATORZE).

É possível perceber que, à exceçẫo da última entrevista, parece permear entre os gestores a ideia de uma visão contemplativa do lazer, para a qual basta a oferta de lugares para que o direito social em questão ocorra. Além disso, o turismo tem uma força importante no município como elemento deflagrador de economia, não como uma ação voltada ao lazer dos cidadãos e que traga repercussão nas políticas sociais. Isso fica claramente explícito na última fala.

Ao se pensar na efetivação do direito ao lazer, as políticas públicas implementadas ainda são muito tímidas no município. Brotas é uma cidade que, no discurso e na realidade, vive um tipo de lazer, que, em tese, é interdisciplinar, o que poderia gerar integração. Elemento catalisador, as práticas corporais de lazer na natureza, se apresentam restritas ao cidadáo brotense, como nos citou alguns dos nossos entrevistados, tornando-se um privilégio para o turista que pode pagar operadoras, que, de certo modo, privatizaram espaços naturais de interesse público.

Não foram encontradas equipes intersetoriais, mas a pequena quantidade de servidores nas Secretarias, a participação nos conselhos municipais e suas relaçôes de amizade permitem-lhes uma maior circulação nesses órgãos, o que resulta algumas vezes em parcerias entre os eventos de lazer aqui analisados. A cultura política na gestão 2009-2012, a estrutura setorializada da Prefeitura Municipal e, ainda, o loteamento político-partidário não impediram que os servidores se organizassem para realizar as açóes e os eventos de lazer na cidade, mas certamente poderiam apresentar-se como uma política forte de lazer na natureza, com caráter de turismo social e ambiental, náo fossem os obstáculos da cultura política e da forma de gestão lá presentes.

Em relaçáo à competência técnica setorial sobre lazer, encontramos técnicos e bacharéis em Turismo e profissionais de Educação Física (nas secretarias de Esporte, Meio Ambiente e Educaçáo), porém somente um deles tem uma visão mais ampla de lazer. Esse profissional pensa o lazer a partir da vivência de atividades no tempo livre em que uma prática de esporte, por exemplo, pode estar vinculada à apreciaçáo do meio ambiente e ao mesmo tempo ser uma prática turística. Além disto, esse profissional mencionou as possibilidades educativas que as atividades de lazer podem proporcionar, além dos benefícios para os indivíduos.

Isso nos leva a concluir que, antes da defesa da interstorialidade, é fundamental a materialização do lazer como política setorial forte e com gestores e técnicos com competência técnica e política capazes de defender e fazer valer suas posiçóes no jogo político. Há que se pensar que tal fato também decorre de uma sustentação argumentativa em prol da democratização do lazer. 


\title{
Nota
}

a. Trade turístico corresponde ao conjunto de agentes do setor privado ligados diretamente ao setor de prestaçáo de serviços para o turismo, como, por exemplo, as agências de viagem e passeios, as operadoras, os meios de hospedagem (hotéis, pousadas, campings etc.), as empresas de transporte, as empresas do setor de alimentação (restaurantes, bares, cafés etc), as lojas de artesanato e souvernirs, empresas de entretenimento (parques de diversões, cinemas, etc.), entre outras entidades empresariais ${ }^{18}$.

\begin{abstract}
Sectorial or intersectoriality? The case of the public policies of leisure in Brotas, São Paulo

The aim of the study were to verify how the public policies of leisure in Brotas / SP in the 2009/2012 management were characterized as regards the presence of intersectoriality. We used documentary analysis, observations the work meetings and semi-structured interviews with managers and servers of those secretariats. The data of the interviews were analyzed through the thematic analysis. We find in the 2009-2012 management indications of intersectoriality more frequently in the events. We conclude, when analyzing the intersectoriality and the right to leisure, that public policies implemented in Brotas are still timid. The sport in the nature are restricted to the Brota's citizen and have become a privilege for the tourist can pay the operators who, in a way, have privatized natural spaces of public interest.
\end{abstract}

KeYwords: Leisure; Public policies; Sectorial administration; Cross-sectorial administration.

\section{Referências}

1. Santos FC. Procurando o lazer na Constituinte: sua inclusão como direito social na Constituição de 1988. [Dissertação]. Campinas: Unicamp, 2011.

2. Menicucci TMG. Políticas públicas de lazer: questôes analíticas e desafios políticos In: Linhales M, Isayama HF, organizadores. Sobre lazer e política: maneiras de ver, maneiras de fazer. Belo Horizonte: UFMG, 2006, p.136-164.

3. Costa ET. Na rede, pelo lado de fora? Gestão matricial e as políticas públicas de lazer na cidade de Santo André, [Dissertação]. Campinas: Unicamp, 2008.

4. Bonalume CR. O esporte e o lazer na formulação de uma política pública intersetorial para a juventude: a experiência do PRONASCI. [Dissertação]. Brasília: Universidade de Brasília, 2010.

5. Amaral SCF. Costa ET. Possibilidades de matricialidade na administração pública do lazer. Movimento. 2012;18;205-220.

6. Menicucci TMG. Intersetorialidade, o desafio atual para as políticas sociais. Pensar BH Pol Social. 2002;10-13.

7. Abreu CC. A intersetorialidade no processo de construção da política de saúde brasileira. [Dissertação]. Vitória: UFES, 2009.

8. Bonalume CR. O Paradigma da intersetorialidade das políticas públicas de esporte e lazer. Rev Licere. 2011:1-26.

9. Silva DS. Intersetorialidade, descentralização e empreendedorismo na gestão pública de esporte e lazer no Estado do Espírito Santo. [Dissertação]. Vitória: UFES, 2012.

10. Amaral SCF. Lazer: temática transversal e intersetorialidade. [Tese de Livre Docência]. Campinas: Unicamp, 2011.

11. Martins L. Reforma da administração pública e cultura política no Brasil: uma visão geral. Brasília: Cadernos ENAP:1997.

12. Paula APP. Por uma nova gestáo pública: limites e potencialidades da experiência contemporânea. Rio de Janeiro: FGV, 2005.

13. Inojosa RM. Intersetorialidade e a configuração de um novo paradigma organizacional. Rev Admin Pública, 1998:35-48.

14. Farah MFS. Parcerias, novos arranjos institucionais e políticas públicas no nível local de governo. Rev Admin Pública, 2001 p.119-44.

15. Pinto LMSM. O lazer no setor público brasileiro e os desafios para a intersetorialidade. In: Fortini JLM, Gomes CL, 
Elizalde R, organizadores. Desafios e perspectivas da educação para o lazer. Belo Horizonte: SESC/Otium, 2011, p.57-68. 16. Minayo MCS, Deslandes SF, Gomes R. Pesquisa social: teoria, método e criatividade. Petrópolis: Vozes, 2009.

17. Brotas. Lei Complementar n. 0012, de 22 de Novembro de 2006. Plano Diretor.

18. Pellegrini Filho A. Dicionário enciclopédico de ecologia e turismo. São Paulo: Manole, 2000.

19. Luna RB. Integração horizontal de ações governamentais. [Dissertação]. São Paulo: Fundação Getúlio Vargas, 2007.

20. Pinto LMSM. O lazer no setor público brasileiro e os desafios para a intersetorialidade. In: Fortini JLM, Gomes CL, Elizalde R, organizadores. Desafios e perspectivas da educação para o lazer. Belo Horizonte: SESC/Otium, 2011, p.57-68.

ENDEREÇO

Olívia Cristina Ferreira Ribeiro Universidade Estadual de Campinas Av. Érico Veríssimo, 701 - Cidade Universitária 13083-851 - Campinas - SP - Brasil E-mail: olivia@fef.unicamp.br

Submetido: 06/05/2015

1a. Revisão: 21/08/2018

2a. Revisão: 05/ 08/2019

Aceito: 24/05/2021 